\title{
DESIGUALDADES SOCIAIS E DESENVOLVIMENTO EM PORTUGAL \\ UM OLHAR À ESCALA REGIONAL E AOS TERRITÓRIOS DE BAIXA DENSIDADE
}

\section{SOCIAL INEQUALITIES AND DEVELOPMENT IN PORTUGAL A LOOK AT THE REGIONAL SCALE AND THE LOW DENSITY TERRITORIES}

\author{
Rosário Mauritti \\ Instituto Universitário de Lisboa (ISCTE-IUL) \& Centro de Investigação e Estudos de Sociologia (CIES-IUL), \\ Edifício Sedas Nunes, Av. das Forças Armadas, 1649-026 Lisboa, Portugal. Email: rosario.mauritti@iscte-iul.pt

\begin{abstract}
Nuno Nunes
Instituto Universitário de Lisboa (ISCTE-IUL) e Centro de Investigação e Estudos de Sociologia (CIES-IUL), Edifício Sedas Nunes, Av. das Forças Armadas, 1649-026 Lisboa, Portugal. Email: nuno.nunes@iscte-iul.pt
\end{abstract} \\ João Emílio Alves \\ Instituto Politécnico de Portalegre (IPPortalegre); Centro de Investigação e Estudos de Sociologia (CIES-IUL) \& \\ Centro de Investigação para a Valorização de Recursos Endógenos (VALORIZA-IPPortalegre). IPPortalegre, \\ Praça do Município, 11, 7300-110 Portalegre, Portugal. Email: j.alves@ipportalegre.pt

\section{Fernando Diogo} \\ Universidade dos Açores (UAçores) \& Centro Interdisciplinar de Ciências Sociais - Pólo da Universidade dos Açores \\ (CICS.NOVA.UAc/CICS.UAc). Rua da Mãe de Deus, 9500-321 Ponta Delgada, Portugal. Email: fernando.ja.diogo@uac.pt
}

\begin{abstract}
Resumo: Como aferir e monitorizar desigualdades sociais na sociedade portuguesa contemporânea, nomeadamente à escala regional? Os debates científicos contemporâneos apelam para que as problemáticas das desigualdades e do desenvolvimento se aproximem entre si. Este artigo pretende ser um contributo para a compreensão das relações entre estas problemáticas, considerando as desigualdades sociais do país, as suas assimetrias regionais e as desvantagens específicas dos territórios de baixa densidade. Para o efeito, analisamos como a demografia, a educação, o emprego, as classes sociais e a saúde estão associadas a desigualdades sociais entre as regiões do território nacional. Os resultados da pesquisa apontam para a persistência, na sociedade portuguesa, de processos de desenvolvimento desiguais à escala regional e no que diz respeito aos territórios de baixa densidade.
\end{abstract}

Palavras-chave: desigualdades sociais, escala regional, territórios de baixa densidade, desenvolvimento.

\begin{abstract}
How to reveal and monitor social inequalities in contemporary Portuguese society, particularly on a regional scale? Contemporary scientific debates call for the problematics of inequality and development to come close to each other. This article intends to contributes to the understanding of the relations between these scientific issues, considering the social inequalities of the country and the specific disadvantages of the low-density territories. To this end, we analyse how demography, education, employment, social classes and health are associated to social inequalities between the regions of the national territory. The empirical results show that in the Portuguese society there is a persistence of unequal development processes at the regional scale and in regard to the low density territories.
\end{abstract}

Keywords: social inequalities, regional scale, low density territories, development. 


\section{Introdução}

O presente artigo propõe uma matriz conceptual, analítica e empírica que permita aferir e monitorizar desigualdades sociais nos territórios de Portugal, nomeadamente à escala regional e nos territórios de baixa densidade.

Os debates científicos contemporâneos apelam, crescentemente, para que as problemáticas das desigualdades e do desenvolvimento se aproximem entre si (Stiglitz, Fitoussi e Durand, 2018a e 2018b). É sob este pressuposto que estão construídas as agendas internacionais do desenvolvimento humano e do desenvolvimento sustentável (OCDE, 2017; ONU, 2015; Sachs, 2017). Este artigo pretende ser um contributo para a compreensão das relações entre estas problemáticas, considerando as assimetrias regionais do país e a saliência que nela assumem os territórios do interior, também denominados por territórios de baixa densidade (Diogo, Mauritti, Alves e Nunes, 2019; Ferrão, 2002; Martins e Figueiredo, 2008).

A matriz teórico-conceptual de partida apoia-se nas teses da sociedade dualista, da semiperiferia, da modernidade inacabada e da heterogeneidade territorial, que marcaram o modo como, particularmente a sociologia, analisou os mais recentes processos de desenvolvimento da sociedade portuguesa (Almeida, 1986; Almeida, Capucha, Costa, Machado e Torres, 2007; Baptista, 2016; Carmo, 2014; Mauritti e Nunes, 2013; Ferrão, 2016a e 2016b; Nunes, 1964; Pinto, 1985; Santos, 1985 e 1990; Viegas e Costa, 1998).

As desigualdades sociais são muito relevantes no contexto português, quer se analise o problema a partir de uma perspetiva mais associada às desigualdades de rendimentos (Albuquerque, Bomba, Matias, Rodrigues, e Matos, 2002; Carmo, 2010; Rodrigues, 2007; Rodrigues, Figueiras e Junqueiro, 2016), quer quando o enfoque incide sobre as interseções e os efeitos cumulativos de natureza sistémica, embora variável, de diversas formas de desigualdade de classe social, educativas, género, territórios, etnicidade - entre outras (Almeida, 2013; Carmo, 2013; Carmo, Carvalho e Cantante, 2015; Costa, 1999; Costa e Mauritti, 2018; Costa, Mauritti, Martins, Nunes e Romão, 2015; Estanque, 2017; Lopes, Louçã e Ferro, 2017; Martins, Mauritti, Nunes, Costa e Romão, 2016; Mauritti, Martins, Nunes, Romão e Costa, 2016; Mauritti e Nunes, 2013).

A partir de uma conceção multidimensional das desigualdades sociais (Carmo e Costa, 2015; Carmo e Nunes, 2013; Costa, 2012; Mauritti, Martins, Nunes, Romão e Costa, 2016; Nunes, 2013), analisam-se as relações estruturais entre condições de vida das populações e contextos territoriais - nos planos sociodemográfico, socioeducativo, socioprofissional e de acesso à saúde - e as suas respetivas manifestações de 
desenvolvimento desigual entre as regiões do território português, e com uma específica atenção para os territórios de baixa densidade.

$\mathrm{O}$ artigo começa por situar, em grandes traços, as principais mudanças sociais que têm atravessado a sociedade portuguesa na sua ligação com os territórios. No ponto seguinte apresenta-se a metodologia da investigação. Segue-se a análise de um conjunto multidimensional de desigualdades e dos seus impactos de desenvolvimento entre as diferentes regiões do país. Na conclusão, e com base nos resultados da pesquisa, sistematizamos algumas orientações para uma política territorializada de redução das desigualdades, considerando a atual fase do desenvolvimento em Portugal.

\section{Desigualdades sociais e desenvolvimento na sociedade portuguesa}

Nas últimas décadas têm sido várias as transformações que têm vindo a reconfigurar os territórios, quer de matriz urbana, quer rural, numa sociedade portuguesa ainda numa fase de modernização inacabada (Almeida, Capucha, Costa, Machado e Torres, 2007; Mauritti e Nunes, 2013; Nunes, 1964; Viegas e Costa, 1998), agravada com a crise global e a austeridade (Blyth, 2013; Carmo, Nunes e Ferreira, 2016; Geiselberger, 2017; Matsaganis e Leventi, 2014; Rodrigues, 2016).

Uma rápida e incisiva mudança estrutural da sociedade portuguesa, resultante dos processos de recomposição social verificados ao longo das últimas décadas, acentuou assimetrias internas ao país. Nestas dinâmicas o mundo rural apenas acompanhou parcialmente muitas das mudanças ocorridas nos territórios urbanos (Carmo, 2011; Carmo, 2014; Diogo, Palos e Silva, 2017; Ferrão, 2016a; Ferrão e Delicado, 2017; Reis e Lima, 1998). Entre essas transformações, são exemplos significativos, especificamente para o caso do mundo rural, dada a sua extensão e intensidade, o declínio da atividade económica (agrícola e também industrial), o envelhecimento e o despovoamento, reforçados por dinâmicas migratórias e alterações profundas nas configurações das classes, familiares e nas relações entre gerações (Carmo, 2007; Ferrão, 1985; O’Neill, 1984; Pinto e Queirós, 2010; Silva, 1994 e 1998; Sobral, 1999; Wall, 1998).

Em relação à estrutura etária da população portuguesa, desde os anos 1960 que se assiste ao sistemático e progressivo envelhecimento, alimentado na base pela diminuição da proporção de crianças e jovens e no topo pelo aumento da proporção de pessoas com 65 e mais anos. Estas dinâmicas são convergentes com tendências que se verificam na generalidade dos países europeus, contudo salientam-se mesmo nesse contexto alargado pela sua intensidade (Mauritti e Nunes, 2013). 
Apesar da modernização económica e social da sociedade portuguesa, diferentemente do que aconteceu na Europa

a industrialização portuguesa, tardia e parcial, não só conservou durante décadas uma enorme proporção de famílias ligadas à agricultura, como não proporcionou a base económica e social para um crescimento e diversificação das atividades terciárias semelhantes à dos países plenamente industrializados. (Machado e Costa, 1998, p. 33)

Estes constrangimentos refletem-se na estrutura social portuguesa, que se mantém ainda bastante carenciada de qualificações escolares e profissionais, evidenciadas na evolução da distribuição das classes sociais em Portugal (Costa, Mauritti, Martins, Machado e Almeida, 2002; Costa, Machado e Almeida, 2009; Costa, Mauritti, Martins, Nunes e Romão, 2018; Mauritti, Martins, Nunes, Romão e Costa, 2016; Mauritti e Nunes, 2013).

Um dos principais obstáculos ao desenvolvimento do país radica, ainda hoje, no baixo nível de qualificações escolares e profissionais da população, transversal ao conjunto do país, mas agravada nos territórios de baixa densidade. Tais défices, com consequências sociais e económicas decisivas de agravamento das desigualdades sociais - internacionais e intranacionais - espelham o nosso atraso comparativamente com a maioria dos países da Europa.

Os desafios colocados à sociedade portuguesa e aos seus territórios no plano da qualificação, modernização e desenvolvimento da estrutura socioprofissional, incitam à necessidade de investimentos alargados nos domínios educativos, do emprego e da proteção social, quando ainda não ultrapassámos a situação de um incipiente estado-providência, com dificuldades acrescidas no exercício das suas funções distributivas e redistributivas (Botelho, Nunes, Mauritti e Craveiro, 2015; Mauritti, Botelho, Nunes e Craveiro, 2015).

\section{Metodologia}

Para a compreensão das relações entre desigualdades sociais e desenvolvimento mobilizaram-se um conjunto de indicadores estatísticos focados principalmente na escala regional (NUTS1 II). Existe já um indicador estatístico do INE que procura ligar território, desenvolvimento e desigualdades, trata-se do Índice Sintético de Desenvolvimento Regional (ISDR - INE, 2017a), publicado com uma periodicidade bianual (últimos dados de 2015, publicados em 2017). Este índice é apresentado tendo como base territorial as regiões NUTS III, e desdobra-se em três (sub)índices: competitividade, coesão e qualidade ambiental. 
O que distingue o nosso trabalho do realizado neste índice respeita à reflexão sobre a problemática do desenvolvimento com base territorial associada à questão das desigualdades, como se tem vindo a referenciar, um trabalho distinto do realizado pelo INE, mais centrado na apresentação de resultados e, ao mesmo tempo, desmultiplicando-se em três temáticas relativamente distintas.

Assim, embora pertencendo ao mesmo tipo de preocupações e tendo alguns pontos de contacto e interceção, o trabalho ora apresentado e o ISDR são, sobretudo, contributos complementares de natureza distinta ${ }^{2}$.

Nos desenvolvimentos analíticos da presente pesquisa optámos por usar como unidade territorial de base as NUTS II, embora em alguns casos recorramos a outras unidades territoriais. Sendo estas regiões uma iniciativa estatística do Eurostat tendo em vista a organização e sistematização de estatísticas regionais (Pordata, 2018), cedo adquiriram uma dimensão que tem vindo a transcender a simples produção de dados. Tais construções classificatórias dos territórios começaram por ser sobretudo "realidades" político-administrativas e estatísticas, e à medida que foram sendo assumidas pelas populações, adquiriram também reconhecimento social, cultural e até identitário.

No caso concreto deste estudo, a explicação para o cruzamento entre os territórios, as desigualdades e o desenvolvimento assenta sempre numa seleção, entre várias dimensões possíveis, de um conjunto de indicadores passíveis de fornecer um contributo válido para a análise das desigualdades da sociedade portuguesa, a uma dupla escala (nacional e regional) do território português.

Neste sentido, a análise demográfica, a par de indicadores centrais relativos à educação, ao emprego, à estrutura de classes (mais especificamente às categorias socioprofissionais) e, por fim, o acesso aos direitos, neste caso específico à saúde, configuram-se como uma seleção de dimensões analíticas com potencial para a discussão das desigualdades e do desenvolvimento português numa perspetiva territorial.

\section{Desigualdades sociais à escala regional e nos territórios de baixa densidade}

Demografia

Os já aludidos binómios urbano/rural e também litoralização/interioridade, são temáticas recorrentes nos estudos demográficos, sociológicos e no âmbito de investigação realizada em outros domínios das ciências sociais. No plano substantivo a sua génese remonta a processos intensos de mobilidade populacional e reconfiguração estrutural da sociedade portuguesa que ocorreram a partir de 

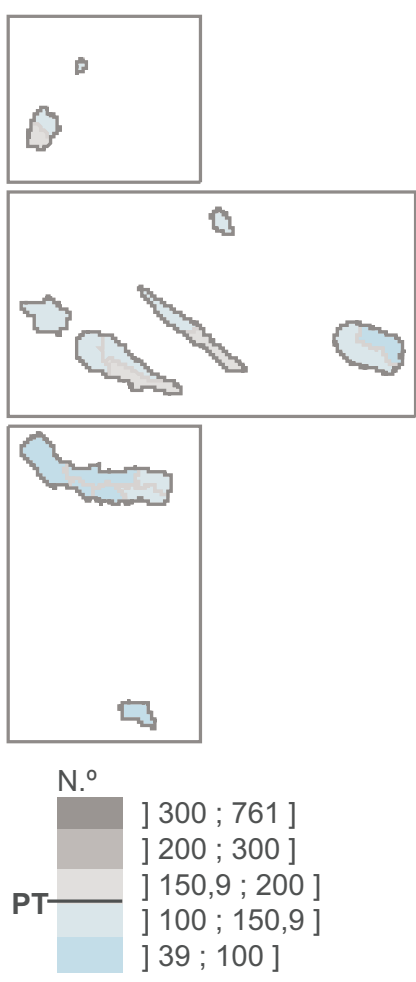

Limites territoriais
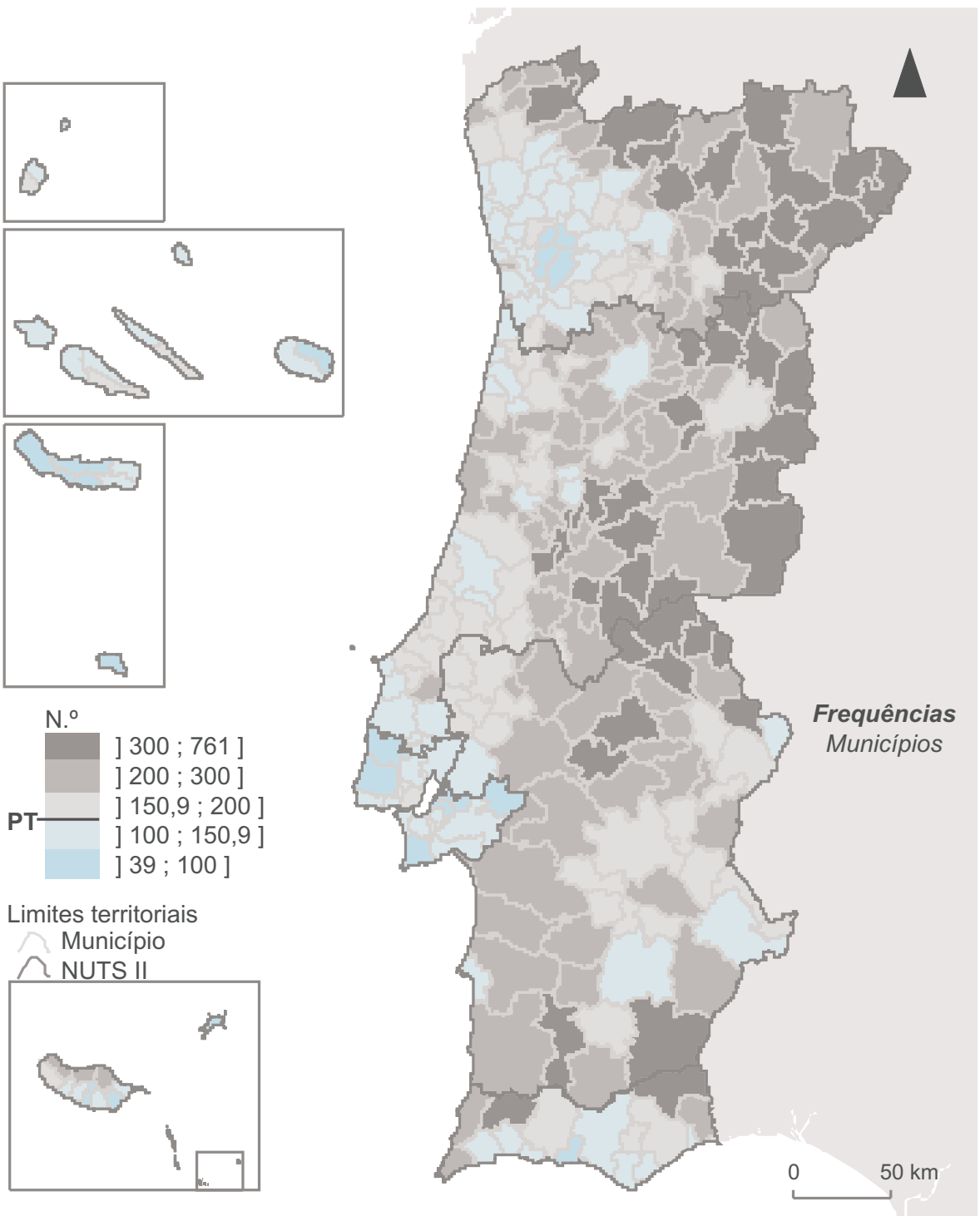

Figura 1 Índice de envelhecimento (2016)

Fonte: INE (2016), Estimativas Anuais da População Residente. Em INE (2017a, p. 96).

finais dos anos 1960, e que hoje se refletem em fortes assimetrias transversais ao território nacional (Mauritti e Nunes, 2013).

De modo simplificado, tais assimetrias no que concerne à distribuição da população podem ser caraterizadas do seguinte modo: cerca de $1 / 3$ da população 
portuguesa reside nas zonas rurais e periféricas, também vulgarmente identificados na literatura sobre o assunto como "territórios do interior" ocupando $81,4 \%$ do território, o que equivale a assumir que, em contrapartida, numa faixa territorial inversa, na ordem dos $19 \%$, tende a concentrar-se uma densidade populacional que envolve os restantes $2 / 3$ da população em Portugal.

Se a esta variável associarmos uma análise dirigida ao índice de envelhecimento $^{3}$ (figura 1), observa-se uma mancha territorial mais expressiva em termos de envelhecimento nos territórios de matriz rural, geograficamente mais próximos da fronteira, e em regiões e concelhos mais afastados dos grandes centros urbanos.

Com efeito, o agravamento do envelhecimento foi particularmente incidente em municípios das sub-regiões do Interior Norte (Alto Tâmega, Terras de Trás-os-Montes e Douro) e Centro (Beiras e Serra da Estrela, Beira Baixa e Médio Tejo), destacando-se os municípios de Almeida, Vila de Rei, Oleiros, Penamacor e Castanheira de Pêra, que registaram um aumento em mais de 100 idosos por 100 jovens.

A situação é particularmente sensível se atendermos ao facto de que a tendência de agravamento do envelhecimento no território nacional, embora constituindo um dado transversal ao país, é mais acentuada nos mesmos territórios (considerados de "baixa densidade") e com perspetiva de agravamento nas próximas décadas, tendo em conta as projeções demográficas conhecidas (INE, 2017b). Aliás, basta atender aos valores reportados ao intervalo temporal entre 2011 e 2016, no qual cerca de $95 \%$ dos municípios portugueses sofreram um agravamento no que respeita ao processo de envelhecimento. Paralelamente, num plano comparativo europeu, Portugal destaca-se, como um dos países que mais concorre para a incidência do mesmo fenómeno, considerando, por exemplo, o facto de na União Europeia, em 2015, existirem 123 idosos para cada 100 crianças/jovens, ao passo que em Portugal, em 2016, esse valor ascendia já a 151 idosos por cada 100 jovens (INE, 2017b).

É assim que Portugal, no contexto dos países do sul da Europa e de forma mais acentuada nas últimas décadas, a que a recente crise económica mundial não terá sido alheia (sendo responsável pelo intenso aumento da emigração, particularmente de população ativa mais qualificada em níveis comparáveis aos anos 1960 do século passado), continua a evidenciar um profundo e estruturante desequilíbrio demográfico, mais expressivo nos territórios classificados como rurais ou periféricos, caracterizados pelo contínuo despovoamento e envelhecimento da população e, por conseguinte, em risco de despovoamento e de desagregação do seu tecido económico e social. As desigualdades no plano demográfico acompanham, assim, de forma estreita a diferenciação dos territórios, em termos de estrutura produtiva e económica (mais agrária e rural a medida que se avança para as regiões periféricas) e também da composição social das populações (rendimentos, qualificações, peso da população ativa, classes sociais, 
etc.), quer também no plano do acesso a serviços fundamentais como a educação e a saúde. Estas assimetrias são notórias quer numa perspetiva diacrónica, quer sincrónica, e tanto no plano interno como europeu.

Esta leitura é complementada pela análise que decorre da figura 2 e 3, que mostra a localização espacial dos territórios do interior (denominados territórios de baixa densidade) por um lado, a relação entre área $\mathrm{km}^{2} /$ e população residente (densidade populacional) por NUT II em 2016.

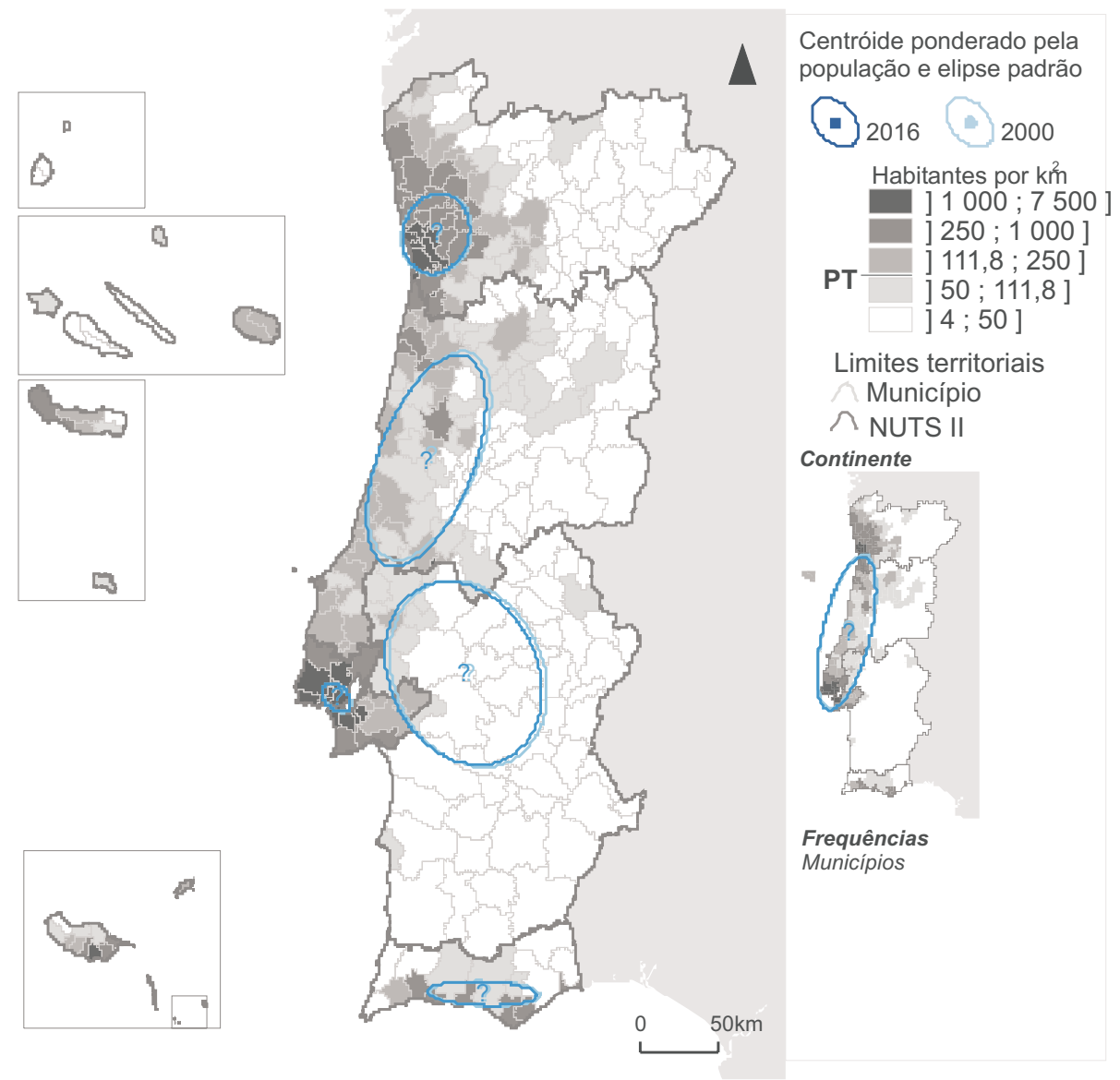

Figura 2 Territórios do Interior — Limites geográficos (Municípios de baixa densidade)

Fonte: INE, I.P., Estimativas Anuais da População Residente. MA-DGT, Carta Administrativa Oficial de Portugal - CAOP. Em INE (2017a, p. 82). 


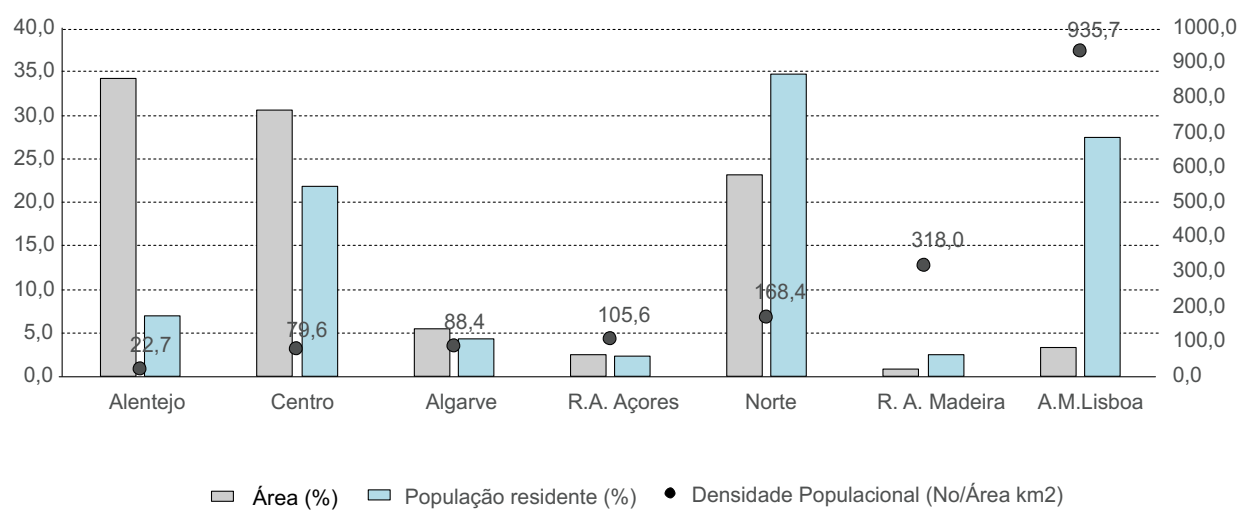

Figura 3 Relação área e população por NUT II - (2016)

Fonte: INE, Portugal em Números 2016, p. 3 (cálculos nossos).

Da análise cruzada da figura 2 e 3 é possível observar uma faixa territorial de grande extensão, recobrindo a maioria dos concelhos do interior do país, contrastando com um menor número de municípios localizados ao longo do litoral, desde o Minho à Área Metropolitana de Lisboa. No caso da figura 3, que apresenta a relação das distribuições percentuais da população e área $(\mathrm{Km} 2)$ nas regiões do Continente e Ilhas por NUT II, e respetiva densidade populacional $\left(\mathrm{N}^{\mathrm{o}}\right.$ médio de habitantes $\left./ \mathrm{km}^{2}\right)$, constata-se que as regiões Alentejo e Centro ocupando $64,8 \%$ da área do território nacional, absorvem apenas $28,7 \%$ da população total residente. O contraste face à Área Metropolitana de Lisboa, cuja área representa apenas 3,4\% do território nacional, concentrando 28,8\% da população, é abissal. O cálculo desta relação entre áreas do território e população através do índice de densidade populacional, destaca para além da Área Metropolitana de Lisboa (cuja densidade populacional é de 936 habitantes por $\mathrm{km}^{2}$ ), a Região Autónoma da Madeira (em 2016, com 318 habitantes $/ \mathrm{km}^{2}$ ). No extremo oposto destas realidades, e de resto numa condição de depressão demográfica singular face a todas as regiões NUT II do país, encontra-se a região do Alentejo (com cerca de $23 \mathrm{hab} / \mathrm{km}^{2}$ ).

\section{Educação}

Como se poderá interpretar a distribuição do capital escolar pelo território nacional? A análise dos dados sobre a educação permite, desde logo, perceber que existem grandes desigualdades entre as regiões. Os indicadores selecionados habilitam uma análise mais limitada a uma outra questão igualmente importante: a das desigualdades dentro de cada região e a forma como essa estrutura de desigualdades compara entre as várias regiões. 


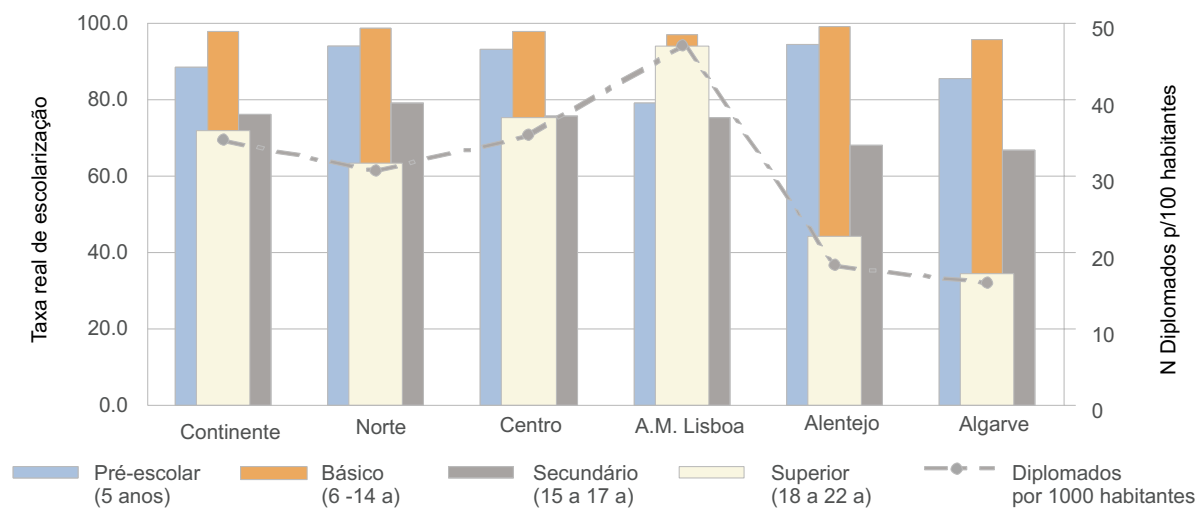

Figura 4 Taxa real de escolarização 2016 e Diplomados por 1000/hab 2015 Fonte: DGEEC, 2017.

Através dos dados apresentados na figura 4 (com informações reportadas apenas às regiões do Continente) procura-se aferir em que medida existe, ou não, um desfasamento nas idades de frequência dos vários patamares de escolaridade, desde o pré-escolar ao ensino superior. Nas situações em que esse desfasamento é nulo ou residual a incidência percentual de "escolarização real" aproxima-se dos $100 \%$, ou seja, o total de crianças e jovens da respetiva coorte geracional ou intervalo de idades estão a frequentar o nível de escolaridade que era esperado.

Apesar do forte investimento no incremento da escolarização e das conquistas, muito significativas, observadas neste domínio, particularmente com a institucionalização da universalidade da educação pré-escolar a partir dos cinco anos de idade e o alargamento da escolaridade obrigatória nos 12 anos para crianças e jovens até 18 anos (Lei 85/2009, de 27 de agosto), ${ }^{4}$ a verdade é que o retrato do país neste domínio mantém-se ainda muito aquém dos objetivos definidos pelas instituições governativas nacionais. Mais ainda, a comparação entre regiões denota, também aqui, fortes assimetrias, por vezes inesperadas. É o caso da taxa real de escolarização no pré-escolar, na Área Metropolitana de Lisboa, patamar em que a incidência de frequência está $20,7 \%$ aquém do que seria esperado. Neste nível pré-escolar e também no ensino básico a região NUT II com melhor performance é o Alentejo (com, respetivamente, 94,3\% e 99,3\% de taxa real de escolarização). Mas esta situação altera-se radicalmente na transição para o secundário e ainda mais na frequência do ensino superior.

Verifica-se que quase $1 / 4$ dos jovens do Continente com idades entre os 15 e os 17 anos, idades em que esperaríamos que frequentassem cursos de nível secundário, 


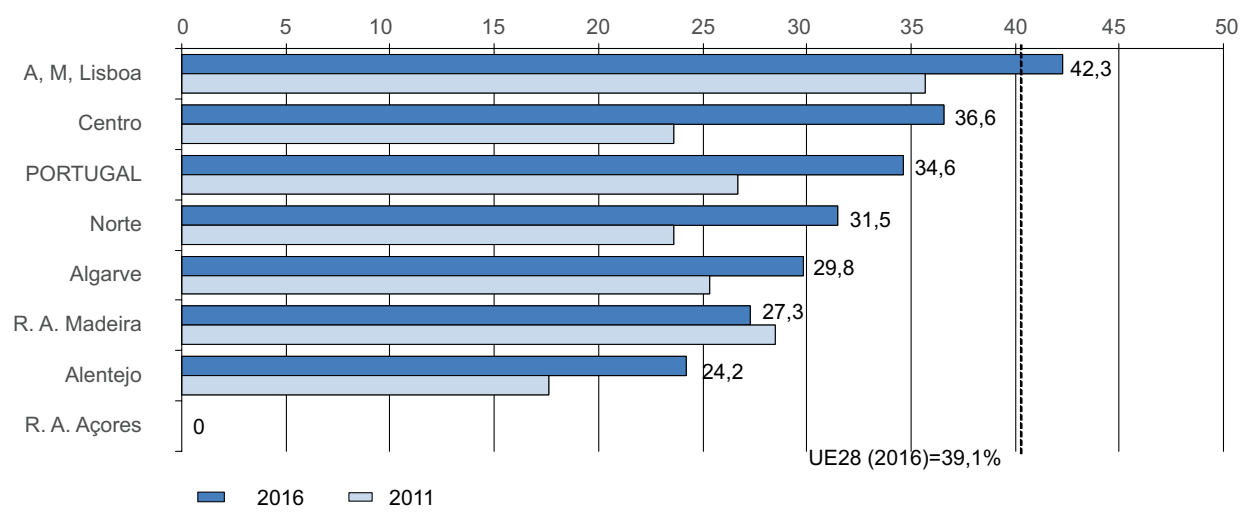

Figura 5 Taxa de diplomados 30-34 anos, Continente, NUTS II 2016

Fonte: INE, Inquérito ao Emprego, série 2011. Eurostat; dados não disponíveis para a R.A. Açores.

não estão neste patamar de escolarização. ${ }^{5}$ Nesta faixa etária, mais do que abandono escolar precoce, o fenómeno evidencia a forte incidência de retenções escolares em ciclos de ensino anteriores, ao longo do nível básico. Sendo uma questão transversal às várias regiões em referência, a sua incidência é ainda assim bastante desigual, opondo nos extremos o Norte (com 79\% de taxa real de escolarização no ensino secundário) e o Algarve (com 67\%).

Ainda no que respeita à escolaridade, é de esperar que as distinções sejam ainda mais evidentes nos ciclos não obrigatórios, dado que nos restantes a pressão para a obrigatoriedade tenderá, pelo menos a prazo, a uniformizar os dados no conjunto do território nacional. Neste sentido, no patamar superior de escolarização, a par das retenções em ciclos de ensino anteriores, a saída precoce do sistema coloca-se como desafio maior.

De facto, neste nível mais elevado de escolarização as desigualdades entre regiões são ainda mais notórias do que nos ciclos de estudo anteriores, opondo a AML (com $47 \%$ de taxa real de escolarização) e a região do Algarve (17\%).

Na figura 4 apresenta-se também o rácio de diplomados por cada 1000 habitantes. No ano letivo 2015/16 esse rácio situa-se entre $94,2 \%$ na região de influência da capital e 31,9\% no extremo sul do país. Ou seja, muito aquém do que constitui a narrativa oficial em relação às metas societais de um país que se descreve no contexto da "sociedade de informação e do conhecimento" e que vê no incremento da população com diploma de estudos superiores uma estratégia nuclear de reposicionamento competitivo quer no quadro de referência da Europa, quer no mundo. 
Tabela 1 População empregada (25-64 anos) por qualificações e escolaridade, segundo NUTS II, 2016

\begin{tabular}{l|c|c|c|c|c}
\hline \multirow{2}{*}{ NUTS II } & \multicolumn{2}{|c|}{ Nível de escolaridade } & \begin{tabular}{c} 
Ativas/os com pelo \\
menos a escolaridade \\
obrigatória no total da \\
\cline { 2 - 4 } população (25-64 anos)
\end{tabular} & $\begin{array}{c}\text { Quadros superiores } \\
\text { e especialistas no total } \\
\text { de empregadas/os }\end{array}$ \\
\hline Portugal & 48,4 & 25,7 & 26,0 & 59,4 & 24,5 \\
Continente & 47,8 & 25,9 & 26,3 & 68,4 & 24,7 \\
Norte & 53,2 & 24,4 & 22,5 & 52,7 & 21,9 \\
Centro & 52,2 & 23,3 & 24,4 & 59,4 & 21,5 \\
A. M. Lisboa & 35,8 & 29,2 & 35,0 & 70,2 & 19,0 \\
Alentejo & 52,4 & 27,7 & 19,9 & 59,3 & 21,3 \\
Algarve & 49,2 & 28,6 & 22,2 & 63,3 & 17,4 \\
R. A. Açores & 59,7 & 21,3 & 18,9 & 45,5 & 21,2 \\
R. A. Madeira & 58,0 & 20,7 & 21,2 & 47,9 & \\
\hline
\end{tabular}

Fonte: INE, Inquérito ao Emprego (30/09/2017).

Neste sentido, a análise da taxa de diplomados entre os 30 e os 34 anos (figura 5) é um indicador particularmente significativo, quer por, em sequência do que se observou anteriormente, ter potencial para sublinhar as diferenças de desenvolvimento inter-regionais, quer porque se trata de um dos indicadores definidos pela União Europeia para monitorizar a Estratégia 2020 (CE, 2018), no que à educação respeita. Este escalão de idades referencia os objetivos de compromisso societal em que os diversos países se inscrevem. No caso de Portugal, o objetivo é atingir pelo menos $40 \%$ de diplomados na coorte geracional em referência até 2020 .

A leitura destes dados sublinha que no plano nacional apenas a região de Lisboa já atingiu o objetivo 2020, sendo a média global obtida para o contexto nacional (na ordem dos $35 \%$ ) uma expressão da persistência de fortes assimetrias regionais. A comparação dos ritmos de incremento das taxas de diplomados observados nas várias regiões denota um forte dinamismo sobretudo da Região Centro, que no período de referência (2011-2016) progride sensivelmente 13 pontos percentuais em termos do peso relativo de diplomados neste grupo etário (R.A. Madeira, no extremo oposto, aumenta a divergência face ao padrão do país, na medida em que apenas incrementa 1,2 p.p.).

A análise da escolaridade na população empregada (25-64 anos) complementa esta abordagem, destacando o perfil qualificacional do segmento populacional que está ativamente investido na atividade económica (tabela 1). Nestes dados, onde estão também incluídas as duas regiões autónomas dos Açores e da Madeira, percebemos o caminho ainda longo que temos a percorrer para atingir um perfil nacional de qualificações compatível com os padrões europeus que referenciam as nossas condições de desenvolvimento e participação na modernidade contemporânea. 
Os dados permitem aprofundar a abrangência das clivagens que opõem diferentes realidades territoriais, do ponto de vista do potencial instalado de inovação e também da sua capacidade para acolher, de forma sustentável, segmentos populacionais com perfis qualificacionais melhorados. A análise destas informações deve ter em conta características dos territórios já analisadas anteriormente, nomeadamente traços sociodemográficos e peso relativo, apesar de tudo, muito diferenciado das gerações mais velhas.

No todo nacional, cerca de $48 \%$ da população empregada com 25 a 64 anos tem níveis de escolaridade abaixo do secundário. A AM Lisboa distingue-se neste indicador por ter o mesmo peso relativo de pessoas com escolaridade básica e superior (35\%); numa distribuição de perfis que dá bem conta de fortes clivagens no interior da região onde se localiza a capital de Portugal. Nas restantes regiões o peso de diplomados tende a ser mais baixo (ou pelo menos muito idêntico, como no Centro) do que o de pessoas detentoras de estudos secundários e em todas o segmento preponderante tem nível de escolaridade que não vai além do básico.

A percentagem de quadros superiores e especialistas, grandes grupos de profissões cujo acesso tem como requisito a posse de recursos qualificacionais e educacionais avançados, envolve sensivelmente $1 / 4$ do total de empregados. Esta proporção é intensificada na região metropolitana de Lisboa (33\%) e mitigada na R.A. dos Açores e no Alentejo (respetivamente 17\% e 20\%).

\section{Emprego}

Prolongando o argumento, desta feita dirigido à taxa de emprego segundo o grupo etário e o sexo, na análise das NUTS II, reportada a 2016 (tabela 2), verifica-se uma taxa de emprego global de 52\% (65\% no escalão teórico que acolhe o grosso da população potencialmente ativa, ou seja, nas idades de 15 a 64 anos). No total de empregados o diferencial por género ronda no plano nacional 10 pontos percetuais (57\% nos homens e $48 \%$ nas mulheres).

Uma análise mais fina e transversal, das interseções entre género, e grupo etário por região, permite observar o desenho de tendências que provavelmente poderão vir a intensificar-se nos próximos anos. Tendências que se articulam, nomeadamente, com a reconfiguração profunda dos perfis qualificacionais segundo o género, nas gerações mais jovens, mais favorável para a população feminina, tendo em conta reconfigurações profundas na atribuição de papéis entre homens e mulheres, no sentido do reconhecimento do mérito (e das qualificações) como critério primordial de acesso aos lugares.

Primeira tendência: a diminuição da décalage de género no que concerne à taxa de empregabilidade à medida que nos reportamos a gerações mais jovens: 
Tabela 2 Taxa de emprego segundo o grupo etário e o sexo, NUTS II, 2016 (\%)

\begin{tabular}{|c|c|c|c|c|c|c|c|c|c|c|c|c|c|}
\hline & \multicolumn{3}{|c|}{ Total } & \multicolumn{3}{|c|}{ 25-34 anos } & \multicolumn{3}{|c|}{$35-44$ anos } & \multicolumn{3}{|c|}{45 e mais anos } & \multirow{2}{*}{$\frac{15-64 \text { anos }}{\mathrm{HM}}$} \\
\hline & $\mathrm{HM}$ & $\mathrm{H}$ & M & $\mathrm{HM}$ & $\mathrm{H}$ & M & $\mathrm{HM}$ & $\mathrm{H}$ & $M$ & $\mathrm{HM}$ & $\mathrm{H}$ & $M$ & \\
\hline Pol & 52,0 & 57,1 & 41 & 78,2 & 78,9 & 77,5 & 84,4 & 87,3 & 7 & 42,0 & 49,3 & 36,0 & 65,2 \\
\hline Norte & 51,4 & 57,7 & 45,8 & 79,7 & 82,2 & 77,3 & 83,0 & 87,4 & 79,0 & 40,8 & 49,2 & 34,0 & 62,9 \\
\hline Centro & 53,5 & 59,6 & 48,2 & 80,9 & 78,9 & 82,8 & 86,8 & 89,4 & 84,5 & 44,6 & 54,0 & 36,8 & 67,5 \\
\hline A. M. Lisboa & 52,1 & 54,9 & 49,6 & 76,3 & 76,0 & 76,6 & 84,8 & 86,9 & 82,9 & 41,3 & 45,7 & 37,9 & 67,1 \\
\hline Alentejo & 48,2 & 54,0 & 43,0 & 75,1 & 78,8 & 71,3 & 84,0 & 88,1 & 79,9 & 38,3 & 45,0 & 32,5 & 64,4 \\
\hline Algarve & 54,2 & 56,9 & 51,9 & 78,0 & 79,1 & 76,9 & 85,6 & 85,3 & 86,0 & 44,5 & 49,2 & 40,6 & 68,4 \\
\hline R. A. Açores & 52,4 & 57,9 & 47,2 & 73,2 & 77,4 & 68,9 & 79,8 & 82,0 & 77,6 & 43,7 & 52,0 & 36,6 & 61,0 \\
\hline R. A. Madeira & 52,6 & 57,3 & 48,6 & 70,6 & 66,8 & 74,5 & 81,6 & 82,1 & 81,1 & 46,8 & 56,6 & 39,7 & 60,7 \\
\hline
\end{tabular}

Nota: Dados reportam à população ativa empregada.

Fonte: INE, Inquérito ao Emprego (30/09/2017).

esse diferencial é de 13 pontos percentuais no segmento com 45 e mais anos; apenas de 1 pp. no segmento 25-34 anos, isto nos dados relativos ao todo nacional.

Segunda tendência: o incremento (e mesmo inversão pontual) da taxa de emprego das mulheres nas gerações mais novas (com deferenciais de escolarização melhorados face aos seus congéneres masculinos, cf. por exemplo, CNE, 2018) sobretudo, nas regiões que apresentam um perfil de maior capacidade de inovação e convergência com o padrão europeu: a Região Centro e a Área Metropolitana de Lisboa. Nestas duas regiões, nos segmentos de idades 25 a 34 anos, a taxa de emprego segundo o género é ligeiramente mais elevada na distribuição feminina. Tal tendência, num contexto em que as mulheres, de forma sistemática ao longo dos últimos anos têm vindo adquirir maior qualificação do que os homens da mesma coorte geracional, aponta quer para a crescente relevância da educação na capacitação para o trabalho; quer também para uma possível reconfiguração, no futuro, de lugares e papéis de mulheres e homens na vida social.

Terceira evidência: num país, como vimos atrás, que sofre uma enorme "sangria" populacional, e que necessita de incrementar de forma sustentável a taxa de atividade e as qualificações profissionais da sua população, fruto dos baixos níveis de educação ainda prevalecentes, sobretudo à medida que progredimos na idade, verifica-se que a taxa de emprego baixa para $42 \%$ (49\% homens; $36 \%$ mulheres) no escalão com 45 e mais anos. ${ }^{6}$

Quarta evidência: as fortes e persistentes assimetrias regionais, em convergência com análises anteriores referenciadas a indicadores demográficos e educacionais. Com efeito, a análise numa perspetiva regional, permite evidenciar alguns desvios face à tendência média nacional. É o caso, por exemplo, da região do Alentejo, quer em termos globais, quer de forma repartida pelos mesmos 
escalões etários, denotando-se, neste caso o "padrão clássico" (prevalecente) de clara desvantagem das mulheres comparativamente aos homens. Esta tendência é particularmente observável nos três escalões etários, sendo reproduzida igualmente nos valores totais apurados para a região. É também, e só nesta região, que, no grupo dos 45 e mais anos, os valores são inferiores a $40 \%$ em termos globais, atingindo apenas $32 \%$ para as mulheres, o que corresponde à percentagem mais baixa no conjunto das NUTS II (embora nesta variável não estejam disponíveis dados para as regiões autónomas).

Em sentido inverso, a AML é a região do país que, como assinalado atrás, apresenta valores mais equitativos no que respeita à paridade entre sexos, sobretudo no escalão etário dos 25 aos 34 anos, mantendo-se, todavia, a diferença entre homens e mulheres nos restantes escalões etários. É também nesta NUT que o valor total da taxa de emprego (52,1\%) é praticamente coincidente com a média nacional (52\%). As regiões Centro e Algarve são as únicas que apresentam valores superiores à média, respetivamente 53,5\% e 54,2\%. Em contraponto, a região do Algarve e do Norte apresentam valores totais inferiores à média nacional, com taxas de emprego de $48,2 \%$ para o primeiro caso e de $51,4 \%$ para o segundo.

Os valores da tabela 3, reportados a 2015, complementam as análises desenvolvidas dando conta das assimetrias regionais a partir da distribuição de rendimentos líquidos (deduzido de impostos) das famílias por escalões fiscais.

Numa leitura global ao nível do país, não constituirá surpresa a observação de que os valores mais expressivos em termos de rendimentos líquidos (anuais) dos portugueses se situem nas categorias "menos de 5000 euros" e "de 5000 a menos de 10000 euros" (com 16\% e 32\%, respetivamente).

Esta distribuição é, aliás, reproduzida em todas as NUTS II, constituindo o intervalo de rendimentos superiores a 32500 euros o menos significativo no conjunto das regiões. Ainda assim, Lisboa apresenta, para esta última categoria de valores, uma percentagem mais expressiva por comparação às restantes regiões $(12 \%)$, seguida da R.A. Açores (com 9,1\%), constituindo as únicas que apresentam valores superiores à média nacional (na ordem dos $8 \%$ ).

Tendência transversal a todas as NUTS II é o facto de as percentagens mais expressivas situarem-se no intervalo entre 5000 e menos de 10000 euros, acompanhando, de resto, a tendência nacional. A região de Lisboa, embora reproduzindo a tendência nacional, é a única que revela valores ligeiramente melhorados nos intervalos de rendimentos mais elevados, designadamente entre os 19000 e menos de 32 500 euros e no já referenciado intervalo de rendimentos superior aos 32500 euros, fator que não será alheio à maior concentração de um contingente de quadros superiores, especialistas e técnicos intermédios, quer da administração pública, quer do 
Tabela 3 Rendimentos líquidos dos agregados fiscais, 2015 ( euros)

\begin{tabular}{l|c|c|c|c|c|c|c}
\hline \multirow{2}{*}{ NUTS II } & $\begin{array}{c}\text { Total } \\
\text { Agregados } \\
\text { fiscais } \\
(\mathrm{N})\end{array}$ & $\begin{array}{c}<5.000 \\
\text { euros }\end{array}$ & $\begin{array}{c}5.000 \\
\mathrm{a}<10.000 \\
\text { euros }\end{array}$ & $\begin{array}{c}10.000 \\
\mathrm{a}<13.500 \\
\text { euros }\end{array}$ & $\begin{array}{c}13.500 \\
\mathrm{a}<19.000 \\
\text { euros }\end{array}$ & $\begin{array}{c}19.000 \\
\mathrm{a}<32.500 \\
\text { euros }\end{array}$ & $\begin{array}{c}>32.500 \\
\text { euros }\end{array}$ \\
\cline { 3 - 8 } & \multicolumn{7}{|c|}{$\%$} \\
\hline Portugal & 5008652 & 16,2 & 32,2 & 14,2 & 14,1 & 15,4 & 8,0 \\
Norte & 4788733 & 17,9 & 34,8 & 13,8 & 13,9 & 13,3 & 6,4 \\
Centro & 1719851 & 15,1 & 34,3 & 14,6 & 14,2 & 15,1 & 6,7 \\
Lisboa & 1079153 & 14,5 & 26,5 & 14,0 & 14,5 & 18,6 & 11,9 \\
Alentejo & 1409087 & 14,4 & 35,6 & 15,3 & 13,9 & 14,6 & 6,2 \\
Algarve & 353235 & 20,6 & 33,6 & 13,9 & 12,8 & 13,4 & 5,6 \\
R.A. Açores & 227407 & 16,9 & 32,0 & 13,6 & 13,2 & 15,2 & 9,1 \\
\hline
\end{tabular}

Nota: Distribuição do número de agregados fiscais por escalões de rendimento bruto declarado deduzido do IRS Liquidado.

Fonte: INE | Ministério das Finanças.

setor empresarial. Esta leitura é aliás confirmada na análise da tabela 4, com a distribuição de rendimentos médios mensais do trabalho por conta de outrem segundo a classe social.

\section{Classes sociais}

$\mathrm{Na}$ tabela 4 desenvolvemos uma operacionalização do indicador de classe social nos segmentos em assalariamento, não incluindo, portanto, quer patrões, quer profissionais liberais ou trabalhadores independentes.

Uma primeira leitura destes dados realça a relação linear e sistemática, em todas as regiões, da relação entre perfis qualificacionais, lugares de classe e rendimentos. Segundo estes dados, claramente, podemos concluir que os dois posicionamentos de classe marcados pela posse de recursos económicos e culturais melhorados (os dirigentes e os profissionais, técnicos e de enquadramento) correspondem aos lugares com maior vantagem em termos de perfil de rendimentos, sempre acima da média de rendimentos na respetiva região.

No extremo oposto, em todas as regiões, ter posicionamento nos segmentos de "trabalhadores não qualificados" significa uma desvantagem, traduzida nos rendimentos médios de trabalho mais baixos do que em qualquer outro posicionamento de classe, na respetiva região.

A comparação dos padrões de rendimentos por regiões faz sobressair Lisboa enquanto única região que apresenta valores acima da média nacional e também a região que apresenta rendimentos médios mais elevados na leitura por segmento de classe social. 
Tabela 4 Rendimentos médios mensais de trabalho por classe social ( euros) - Segmentos em assalariamento

\begin{tabular}{lrrrrrrr}
\hline NUT II & Total & Dirigentes & $\begin{array}{c}\text { Profissionais } \\
\text { técnicos e de } \\
\text { enquadramento }\end{array}$ & $\begin{array}{c}\text { Empregados } \\
\text { executantes }\end{array}$ & Operários & $\begin{array}{c}\text { Assalariados } \\
\text { Agrícolas }\end{array}$ & $\begin{array}{c}\text { Trabalhadores } \\
\text { não qualificados }\end{array}$ \\
\hline Portugal & 1094,13 & 2435,32 & 1631,58 & 905,46 & 851,79 & 765,10 & 690,93 \\
Continente & 1096,66 & 2441,31 & 1632,08 & 905,03 & 850,47 & 767,63 & 688,24 \\
Norte & 975,01 & 2032,62 & 1478,63 & 851,66 & 774,26 & 757,03 & 674,25 \\
Centro & 950,55 & 1799,12 & 1363,50 & 833,13 & 861,62 & 720,68 & 671,38 \\
Lisboa & 1380,08 & 3361,10 & 1879,95 & 997,64 & 1010,84 & 838,15 & 720,56 \\
Alentejo & 994,42 & 1809,82 & 1504,45 & 860,33 & 975,20 & 781,48 & 688,78 \\
Algarve & 926,13 & 1675,46 & 1360,39 & 881,35 & 846,99 & 799,21 & 693,77 \\
Açores & 986,03 & 1975,47 & 1574,00 & 912,19 & 815,16 & 721,61 & 717,22 \\
\hline
\end{tabular}

Nota: Este quadro reporta apenas categorias de classe em situação de assalariamento. A construção do indicador de classe segue os procedimentos descritos em Mauritti e Nunes, 2013, p. 41.

Fonte: INE| MTSS, Quadros de Pessoal; dados não disponíveis para a R.A. Madeira.

Mas se esta região, onde se localiza a capital, se destaca por ter os rendimentos mais elevados é também a que se destaca por apresentar as maiores desigualdades de rendimentos entre categorias de classe. Com efeitos, em Lisboa (onde se concentram as sedes de grandes empresas, assim como a cúpula da administração pública central) as desigualdades de rendimento mensal entre os dirigentes e as outras categorias socioprofissionais (incluindo profissionais técnicos e de enquadramento) são muito notórias. Além disso, o rendimento dos empregados não qualificados é de apenas $21,4 \%$ do equivalente dos dirigentes (a média nacional é de $28,4 \%$ ).

Todas as restantes regiões apresentam valores bastante mais próximos entre si e distantes desta, com destaque para os Açores, pela positiva e o Algarve pela negativa (região onde o rendimento médio mensal do trabalho é mais baixo). De resto, o único valor que se destaca numa comparação dentro de cada grupo, nas diversas regiões, é o dos dirigentes no Algarve, muito abaixo da média desta categoria na comparação nacional e com as restantes regiões.

\section{Saúde}

A saúde é umas das dimensões que os cidadãos mais tendem a valorizar condicionando significativamente as condições de participação social, ao nível da educação, do mercado de trabalho e da produtividade, e também de forma geral o bem-estar, e as relações sociais das populações.

Tendo presente a relevância da saúde, analisamos indicadores sobre condições materiais oferecidas, pelas diferentes regiões, no acesso aos direitos na área da saúde. Neste âmbito, tomando como indicadores específicos os números de profissionais de saúde (enfermeiros e médicos); farmácias por 1000 habitantes; internamentos 
Tabela 5 Indicadores de acesso à saúde (2015 e 2016) (\%)

\begin{tabular}{|c|c|c|c|c|c|}
\hline & Enfermeiras/os & Médicas/os & Farmácias & $\begin{array}{l}\text { Internamentos } \\
\text { hospitalares }\end{array}$ & $\begin{array}{c}\text { Consultas médicas } \\
\text { no hospital }\end{array}$ \\
\hline & \multicolumn{3}{|c|}{$\%$} & $\%$ & N por hab. \\
\hline & \multicolumn{3}{|c|}{2016} & \multicolumn{2}{|c|}{2015} \\
\hline Portugal & 6,7 & 4,9 & 0,3 & 111,3 & 1,8 \\
\hline Norte & 6,7 & 4,8 & 0,3 & 111,9 & 2,0 \\
\hline Centro & 6,8 & 4,4 & 0,4 & 106,1 & 1,5 \\
\hline A.M. Lisboa & 6,8 & 6,3 & 0,3 & 129,0 & 2,2 \\
\hline Alentejo & 6,1 & 2,8 & 0,5 & 73,9 & 1,0 \\
\hline Algarve & 6,0 & 3,8 & 0,3 & 89,4 & 1,1 \\
\hline Açores & 8,3 & 3,1 & 0,3 & 112,7 & 1,2 \\
\hline
\end{tabular}

Fonte: INE, Estatísticas do Pessoal de Saúde, e Estatísticas dos Estabelecimentos de Saúde.

hospitalares, e número de consultas médicas em hospitais por habitante (tabela 5).

Num primeiro olhar dirigido ao número de profissionais de saúde por 1000 habitantes e no caso específico dos enfermeiros/as, a generalidade das regiões acompanha a média nacional situada nos 6,7\%. É o caso das regiões Norte, Centro e AML, apresentando estas duas últimas uma diferença de uma milésima face ao valor médio apurado para o conjunto do país. Apenas a região dos Açores revela uma taxa superior à média nacional, atingindo os $8 \%$, neste caso, a necessidade de dotar as várias ilhas com profissionais deverá ser a justificação da discrepância. Inversamente, as regiões do Alentejo e do Algarve revelam taxas inferiores à média nacional, respetivamente $6,1 \%$ e $6,0 \%$.

No caso do número de médicos por 1000 habitantes, as diferenças de valores das regiões para a média nacional ganham outra expressão. Com efeito, ao passo que o valor nacional se cifra na ordem dos 4,9 médicos por 1000 habitantes, apenas a região da $A M L$ apresenta um valor superior $(6,3 \%)$, reproduzindo a mesma tendência observada na generalidade dos indicadores convocados para este estudo. Todas as restantes regiões apresentam valores inferiores à média do país, sendo particularmente visível nas regiões do Algarve, Açores e Alentejo, com valores inferiores a 4 médicos por 1000 habitantes, atingindo nesta última região o valor mais baixo do conjunto das NUTS II analisadas (apenas 2,8 médicos por 1000 habitantes) $)^{7}$.

No que respeita ao número de farmácias por 1000 habitantes verificam-se valores relativamente distintos dos anteriores. Neste caso é a região Alentejo a que apresenta um valor mais expressivo $(0,5)$, inclusivamente superior à média nacional $(0,3)$, a par da região Centro $(0,4)$. As restantes regiões reproduzem a média nacional, situada em 0,3 farmácias por 1000 habitantes. 
Se, de forma complementar, olharmos para o indicador "percentagem de internamentos hospitalares por 1000 habitantes", os dados reportados a 2015, tendem a prolongar as tendências regionais verificadas a respeito dos indicadores anteriores. Isto é, voltam a ser as regiões do Alentejo, Centro e Algarve as que evidenciam valores mais baixos por relação ao valor médio apurado para o país, com particular expressão para a primeira região (73,9\%). Em sentido contrário, surgem as regiões AML, Norte e Açores com valores acima da média nacional, com destaque para a primeira.

No que concerne ao número de consultas médicas hospitalares por habitante, reproduz-se a mesma distribuição verificada a respeito do indicador anterior, com a diferença da região dos Açores passar a integrar, neste particular, o grupo das NUTS II com valores inferiores à média nacional. Também aqui, voltam a ser a AML e o Norte as regiões que apresentam valores superiores à média do país, situada nas 1,8 consultas médicas hospitalares por habitante.

De notar que os valores da AML e do Norte podem estar empolados pelo facto de em Lisboa e Porto se receberem doentes de todo o país e as restantes regiões apresentarem valores subestimados pelo mesmo fenómeno.

\section{Conclusão}

A análise das relações entre território e desigualdades sociais, com incidência nas distintas configurações estruturais e institucionais das regiões nacionais, nomeadamente as que dizem respeito à demografia, à educação, ao emprego, às classes sociais e à saúde, constituíram um ângulo de análise privilegiado de identificação dos processos de desenvolvimento desigual da sociedade portuguesa.

Os resultados apurados mostram, genericamente, a persistência de um conjunto de desigualdades sobretudo com maior incidência em territórios, essencialmente de matriz rural e mais afastados dos grandes centros urbanos e dos seus perímetros territoriais de influência. Em particular, as regiões do Alentejo, do arquipélago dos Açores e do Centro, constituem uma ilustração desta leitura. Em sentido contrário, as regiões do Norte e, sobretudo a Região Metropolitana de Lisboa, apresentam valores que tendem a posicionar estes territórios num contexto mais favorável tendo em conta os indicadores analisados.

Uma política de redução das desigualdades e com um enfoque particular sobre os territórios de baixa densidade, poderá ser construída e monitorizada a partir das cinco dimensões analíticas aqui desenvolvidas: demografia, educação, emprego, classes sociais e saúde. Aliás, será indispensável que assim seja para que Portugal atinja as metas com que se comprometeu com a comunidade internacional no 
âmbito da Agenda 2030 para o Desenvolvimento Sustentável. O Objetivo 10 de "Redução das Desigualdades no Interior dos Países" só será alcançado intervindo efetivamente sobre as desigualdades sociais que se observam à escala regional na sociedade portuguesa.

As políticas de desenvolvimento (públicas, privadas e comunitárias) terão um papel relevante a desempenhar, interligando estratégias de ação capazes de: 1) diminuir as atuais tendências de envelhecimento, despovoamento e desertificação; 2) aumentar e melhorar a oferta e os perfis educativos desde o pré-escolar até ao ensino universitário; 3) aumentar o emprego, o emprego feminino em determinados escalões etários e valorizar os salários, sobretudo os mais baixos; 4) diminuir as desigualdades de rendimentos e investir na formação e na qualificação das classes mais baixas; e 5) melhorar serviços de assistência média e aumentar o número de médicos e incentivá-los a exercerem a sua profissão fora das áreas metropolitanas.

É no contexto de inserção europeia e internacional que deveremos interpretar a atual fase de desenvolvimento da sociedade portuguesa, ainda marcada pelas suas fortes e duradouras desigualdades sociais, intranacionais e no país como um todo, quando e cada vez mais, a coesão social europeia e as agendas internacionais do desenvolvimento humano e sustentável, são tomadas como os principais horizontes referenciais do desenvolvimento europeu.

A modernidade não é inexorável na sua trajetória de desenvolvimento, em Portugal e no contexto mundial, e a recente crise global veio comprovar como as trajetórias de cada país estão longe de serem lineares. O olhar sociológico sobre as estruturas sociais permite compreender como a reprodução e a mudança social ocorrem num determinado espaço/tempo, e que tendências estão a tomar, como aqui fizemos ao analisar indicadores recentes sobre um conjunto de desigualdades sociais.

Na sociedade portuguesa continuam a persistir traços de uma modernidade inacabada (Mauritti e Nunes, 2013; Viegas e Costa, 1998), e a sua trajetória de desenvolvimento é marcada por assimetrias regionais geradas por desigualdades sociais que comprometem a coesão social do território nacional, nomeadamente quanto aos seus específicos impactos nos domínios da demografia, educação, emprego, classes sociais e saúde.

No debate científico internacional, as abordagens sobre a desigualdade social, começam a afirmar-se na interpretação das dinâmicas de desenvolvimento das sociedades contemporâneas. Foi sob esta perspetiva que procurámos contribuir para este debate, analisando a sociedade portuguesa à escala regional e com particular enfoque sobre os territórios de baixa densidade ${ }^{8}$. 


\section{Notas}

1 NUTS - Nomenclatura das Unidades Territoriais para Fins Estatísticos.

2 Damos também conta da existência de um outro trabalho sobre a distribuição social das desigualdades, desenvolvido pelo IESE, Instituto de Estudos Sociais e Económicos, para a Segurança Social (2015). Neste estudo, é feita uma abordagem do território do continente permitindo construir dois índices distintos, embora ambos tendo como preocupação de base a pobreza e a exclusão social. A unidade territorial de base neste estudo é o concelho e a técnica de tratamento estatístico utilizada permitiu a agregação destes em diferentes perfis. Sendo um contributo para a questão da relação entre território e desenvolvimento, o seu enfoque é, não obstante, apenas a coesão social. Esta é uma questão que, ao mesmo tempo, se apresenta como muito específica e muito genérica em contraste com os objetivos deste artigo.

3 Entendido como o número de pessoas com 65 e mais anos por cada 100 pessoas menores de 15 anos. Um valor superior a 100 significa que há mais idosos do que jovens. Em Portugal a partir de 2000 o índice nacional passou a ser superior a 100.

4 Ficaram abrangidos por esta obrigatoriedade os jovens que frequentavam o $7^{\circ}$ ano do ensino ( $3^{\circ}$ ciclo do básico) ou nível abaixo (se tivesse, entretanto, tido alguma retenção) em 2009/2010 (Diogo, Palos e Silva, 2017).

5 Esta faixa etária dos 15 a 17 anos, foi recentemente assinalada no Relatório Anual de Avaliação da Atividade das CPCJ do ano de 2018 (CNPDPCJ, 2019), como a que acolhe maior incidência de situações diagnosticadas de jovens em "perigo de direito à educação". Num total de 2422 casos assinalados nesta categoria, 54,1\% são desta faixa etária, e destes perto de $1 / 3$ são do sexo masculino.

6 Nesta análise, optamos por manter o escalão de idades dos trabalhadores mais velhos (45 e mais anos) em aberto. Nesta opção temos em conta vários fatores: 1) o facto de Portugal estar entre os países europeus em que as pessoas trabalham até mais tarde (cf. Guerreiro, 2000); 2) o facto de ao contrário de outros países, o dever de resposta aos Inquérito do INE ter um caráter obrigatório, independentemente da idade da pessoa adulta; 3) o facto de no setor privado não haver formalmente limites à permanência na atividade económica.

7 Refira-se a este propósito que no contexto da OCDE, a região Alentejo é apontada como a região com pior rácio médico/doente (OCDE, 2016).

8 Os autores escrevem segundo o acordo ortográfico.

\section{Referências}

Albuquerque, J. L., Bomba, T., Matias, I., Rodrigues, C. F., e Matos, G. (2002).

Distribuição de rendimentos e condições de vida. In VV AA (Ed.), Portugal

1995-2000: Perspectivas da evolução social (pp. 67-86). Oeiras: DEPP/MTS/Celta.

Almeida, J. F. (1986). Classes sociais nos campos. Oeiras: Celta Editora.

Almeida, J. F. (2013). Desigualdades e perspetivas dos cidadãos: Portugal e a Europa. Lisboa: 
Mundos Sociais.

Almeida, J. F., Capucha, L., Costa, A. F., Machado, F. L., e Torres, A. (2007). A sociedade. In A. Reis (Org.), Retrato de Portugal. Factos e acontecimentos (pp. 43-79). Rio de Mouro: Instituto de Camões, Círculo de Leitores e Temas \& Debates.

Baptista, L. V. (2016). Para lá das evidências. Uma reflexão sociológica sobre como observar as realidades territoriais. In F. L. Machado, A. N. Almeida, e A. F. Costa (Orgs.), Sociologia e sociedade. Estudos de homenagem a João Ferreira de Almeida (pp. 213-227). Lisboa: Mundos Sociais.

Blyth, M. (2013). Austerity: The history of a dangerous idea. New York: Oxford University Press.

Botelho, M. C., Nunes, N., Mauritti, R., e Craveiro, D. (2015). Tendências de mudança das funções do Estado em Portugal. In A. F. Costa, e R. M. Carmo (Orgs.), Desigualdades em questão. Análises e problemáticas (pp. 59-75). Lisboa: Mundos Sociais.

Carmo, R. M. (2007). De aldeia a subúrbio: Trinta anos de uma comunidade alentejana. Lisboa: Imprensa de Ciências Sociais.

Carmo, R. M. (Org.) (2010). Desigualdades sociais 2010: Estudos e indicadores. Lisboa: Mundos Sociais.

Carmo, R. M. (Org.) (2011). Entre as cidades e a serra. Mobilidades, capital social e associativismo no interior algarvio. Lisboa: Mundos Sociais.

Carmo, R. M. (Org.) (2013). Portugal, uma sociedade de classes. Lisboa: Edições 70.

Carmo, R. M. (2014). Sociologia dos territórios: Teorias, estruturas e deambulações. Lisboa: Mundos Sociais.

Carmo, R. M., Carvalho, M., e Cantante, F. (2015). The persistence of class inequality: The Portuguese labour force at the turn of the millennium. Sociological Research Online, 20(4), 1-17.

Carmo, R. M., e Costa, A. F. (Orgs.) (2015). Desigualdades em questão. Análises e problemáticas. Lisboa: Mundos Sociais.

Carmo, R. M., e Nunes, N. (2013). Class and social capital in Europe: A transnational analysis of the European Social Survey. European Societies, 15(3), 373-387.

Carmo, R. M., Nunes, N., e Ferreira, D. (2016). Desigualdades, perceções da crise e ação coletiva na Área Metropolitana de Lisboa. In F. L. Machado, A. N. Almeida, e A. F. Costa (Orgs.), Sociologia e sociedade: Estudos de homenagem a João Ferreira de Almeida (pp. 159-174). Lisboa: Mundos Sociais.

CE - Comissão Europeia. (2018). Estratégia Europa 2020. Disponível em https:/ / ec.europa.eu/info/business-economy-euro/economic-and-fiscal-policy-co ordination/eu-economic-governance-monitoring-prevention-correction/european -semester/framework/europe-2020-strategy_pt.

CNE - Conselho Nacional de Educação. (2018). Estado da educação 2017. Lisboa: CNE.

Costa, A. F. (1999). Sociedade de bairro: Dinâmicas sociais da identidade cultural. Lisboa: Celta.

Costa, A. F. (2012). Desigualdades sociais contemporâneas. Lisboa: Mundos Sociais. 
Costa, A. F., Machado, F. L., e Almeida, J. F. (2009). Social classes and educational assets: A transnational analysis. In A. F. Costa, F. L. Machado, e P. Ávila (Orgs.), Knowledge and society: Portugal in the European context (Vol. II) (pp. 5-20). Oeiras, Celta Editora.

Costa, A. F., e Mauritti, R. (2018). Classes sociais e interseções de desigualdades: Portugal e a Europa. In R. M. Carmo, J. Sebastião, J. Azevedo, S. C. Martins, e A. F. Costa (Orgs.), Desigualdades sociais. Portugal e a Europa (pp. 109-129). Lisboa: Mundos Sociais.

Costa, A. F., Mauritti R., Martins, S. C., Machado, F. L., e Almeida, J. F. (2002). Social classes in Europe. Portuguese Journal of Social Science, 1(1), 5-39.

Costa, A. F., Mauritti, R., Martins, S. C., Nunes, N., e Romão, A. L. (2015). A constituição de um espaço Europeu de desigualdades (Observatório das Desigualdades e-Working Paper, n. ${ }^{\circ}$ 1/2015, pp.1-21). Lisboa: ISCTE-IUL, CIES-IUL. Disponível em http://wp.me/P4h6tu-p3.

Costa, A. F., Mauritti, R., Martins, S. C., Nunes, N., e Romão, A. L. (2018). Distributional and categorical inequalities in Europe: Structural configurations. In R. M. Carmo, C. Rio, e M. Medgyesi (Orgs.), Reducing inequalities: A challenge for the European Union? (pp. 63-74). London: Palgrave Macmillan.

Diogo. F., Mauritti. R., Alves, J. E., e Nunes, N. (2019) (no prelo). Desigualdades e desenvolvimento na sociedade portuguesa: Um olhar sociológico à escala nacional e regional. In Atas do X Congresso Português e Sociologia: Na Era da pós-verdade. Esfera Pública. Cidadania e Qualidade da Democracia no Portugal Contemporâneo, Covilhã, Universidade da Beira Interior.

Diogo, F., Palos, A. C., e Silva, O. (2017). Da escola para o mundo do trabalho, perfis de transição para a vida ativa. In G. P. N. Rocha, R. L. Gonçalves, e P. D. de Medeiros (Eds.), Juventude(s): Pensar e agir (pp. 253-280). V. N. Famalicão: Edições Húmus.

DGEEC - Direcção Geral de Estatísticas sobre a Educação (2017). Disponível em http://www.dgeec.mec.pt/np4/dgeec.

Estanque, E. (2017). Onde pára a classe média?. Sociologia, Problemas e Práticas, 83, 37-54.

Ferrão, J. (1985). Recomposição social e estruturas regionais de classes (1970-1981). Análise Social, XXI(87-88-89), 565-604.

Ferrão, J. (2002). Portugal, três geografias em recombinação: Espacialidades, mapas cognitivos e identidades territoriais. Lusotopie, II(9), 151-158.

Ferrão, J. (2016a). Ruralidades e território no capitalismo contemporâneo. Uma visão de longa duração sobre Portugal. In F. L. Machado, A. N. Almeida, e A. F. Costa (Orgs.), Sociologia e sociedade. Estudos de homenagem a João Ferreira de Almeida (pp. 229-245). Lisboa: Mundos Sociais.

Ferrão, J. (2016b). O território na constituição da República Portuguesa (1976-2005). Dos preceitos fundadores às políticas de território do futuro. Sociologia, Problemas e Práticas, (Número Especial), 123-134.

Ferrão, J., e Delicado, A. (Orgs.) (2017). Portugal social em mudança. Retratos municipais. Lisboa: ICS-UL. 
Geiselberger, H. (Org.) (2017). The great recession. Cambridge: Polity Press.

Guerreiro, M. D. (2000). Older workers in Portugal. Paper apresentado no NIDI Seminar, The Future of Elderly Workers, NIDI, Haia, Holanda.

IESE. (2015). Referencial de coesão social 2014. Lisboa: Instituto de Segurança Social.

INE. (2017a). Retrato territorial de Portugal. Lisboa: INE.

INE. (2017b). Desenvolvimento regional global, competitividade, coesão e qualidade ambiental, 2015. Lisboa: INE.

Lopes, J. T., Louçã, F., e Ferro, L. (2017). As classes populares. Lisboa: Bertrand.

Machado, F. L., e Costa, A. F. (1998). Processos de uma modernidade inacabada. In J. M. Viegas, e A. F. Costa (Orgs.), Portugal, que modernidade (pp. 17-44). Oeiras: Celta Editora.

Martins, N., e Figueiredo C. (2008). PROVERE. Programa de Valorização Económica dos Recursos Endógenos. Das ideias à ação: Visão e parcerias. Lisboa: DPP.

Martins, S. C., Mauritti, R., Nunes, N., Costa, A. F., e Romão, A. L. (2016). A educação ainda é importante para a mobilidade social? Uma perspetiva das desigualdades educacionais da Europa do Sul no contexto europeu. Revista Portuguesa de Educação, 29(2), 261-285.

Matsaganis, M., e Leventi, C. (2014). The distributional impact of austerity and the recession in Southern Europe. South European Society and Politics, 19(3), 393-412.

Mauritti, R., Botelho, M. C., Nunes N., e Craveiro, D. (2015). A austeridade na educação (Observatório das Desigualdades e-Working Paper, N. ${ }^{\circ}$ 3/2015, pp. 3-20). ISCTE-IUL, CIES-IUL. DOI: 10.15847/CIESODWP032015.

Mauritti, R., Martins, S. C., Nunes, N., Romão, A. L., e Costa, A. F. (2016). The social structure of European inequality: A multidimensional perspective. Sociologia, Problemas e Práticas, 81, 75-93.

Mauritti, R., e Nunes, N. (2013). Processos de recomposição social: Continuidades e mudanças. In R. M. Carmo (Org.), Portugal uma sociedade de classes: Polarização social e vulnerabilidade (pp. 29-48). Lisboa: Edições 70/Le Monde Diplomátique.

Nunes, A. (1964). Portugal: Sociedade dualista em evolução. Análise Social, 2(7-8), 407-462.

Nunes, N. (2013). Desigualdades sociais e práticas de ação coletiva na Europa. Lisboa: Mundos Sociais.

OCDE. (2016). Health at a glance: State of health in the EU cycle. Paris: OCDE.

OCDE. (2017). How's life? Measuring well-being. OECD Publishing: Paris.

O’Neill, B. J. (1984). Proprietários, lavradores e jornaleiros. Desigualdade social numa aldeia transmontana (1870-1976). Lisboa: Publicações Dom Quixote.

ONU. (2015). Transforming our world: The 2030 agenda for sustainable development (A/RES/70/1). ONU. Disponível em www.refworld.org/docid/57b6e3e44.html.

Pinto, J. M. (1985). Estruturas sociais e práticas simbólico-ideológicas nos campos. Elementos de teoria e de pesquisa empírica. Porto: Edições Afrontamento.

Pinto, J. M., e Queirós, J. (Orgs.) (2010). Ir e voltar. Sociologia de uma colectividade local do noroeste português. Porto: Edições Afrontamento. 
Pordata. (2018). O que são NUTS?. Disponível em https://www.pordata.pt/O+que+sao+NUTS.

Reis, M., e Lima, A. V. (1998). Desenvolvimento, território e ambiente. In J. M. Viegas, e A. F. Costa (Orgs.), Portugal, que modernidade (pp. 329-363). Oeiras: Celta Editora.

Rodrigues, C. F. (2007). Distribuição do rendimento, desigualdade e pobreza: Portugal nos anos 90. Coimbra: Almedina.

Rodrigues, C. F. (Org.) (2016). Desigualdade do rendimento e pobreza em Portugal: As consequências sociais do programa de ajustamento. Lisboa: Fundação Francisco Manuel dos Santos.

Rodrigues, C. F. (Coord.), Figueiras, R., e Junqueiro, V. (2016). Desigualdade de rendimento e pobreza em Portugal 2009-2014. Lisboa: Fundação Francisco Manuel dos Santos.

Sachs, J. (2017). A era do desenvolvimento sustentável. Lisboa: Conjuntura Atual.

Santos, B. S. (1985). Estado e sociedade na semiperiferia europeia do sistema mundial: O caso português. Análise Social, (87/88/89), 869-901.

Santos, B. S. (1990). Estado e sociedade em Portugal (1974-1988). Porto: Edições Afrontamento.

Silva, A. S. (1994). Tempos cruzados. Um estudo interpretativo da cultura popular. Porto: Edições Afrontamento.

Silva, M. C. (1998). Resistir e adaptar-se. Constrangimentos e estratégias camponesas no noroeste de Portugal. Porto: Edições Afrontamento.

Sobral, J. M. (1999). Trajectos. O presente e o passado na vida de uma freguesia da Beira. Lisboa: Imprensa de Ciências Sociais.

Stiglitz, J. E., Fitoussi, J., e Durand, M. (2018a). Beyond GDP: Measuring what counts for economic and social performance. Paris: OECD Publishing.

Stiglitz, J. E., Fitoussi, J., e Durand, M. (Orgs.) (2018b). For good measure: Advancing research on well-being metrics beyond GDP. Paris: OECD Publishing.

UMVI - Unidade de Missão para a Valorização do Interior (2016). Programa Nacional para a Coesão Territorial. Disponível em

http://www.portugal.gov.pt/pt/gc21/governo/programa/programa-nacional-p ara-a-coesao-territorial-/ficheiros-coesao-territorial/programa-nacional-para-a-coe sao-territorial-implementacao-acompanhamento-e-monitorizacao-pdf.aspx.

Viegas, J. M. L., e Costa A. F. (Orgs.) (1998). Portugal, que modernidade?. Oeiras: Celta Editora.

Wall, K. (1998). Famílias no campo. Passado e presente em duas famílias do Baixo-Minho. Lisboa: Publicações Dom Quixote.

Data de submissão: 12/03/2019 | Data de aceitação: 14/06/2019 